\title{
Analisa Pola Penjualan Produk Sepeda Motor Yamaha Menggunakan Metode Algoritma Apriori
}

\author{
Siti Nurlela, Lilyani Asri Utami* \\ Prodi Sistem Informasi, Universitas Nusa Mandiri, Jakarta, Indonesia \\ Email: ${ }^{1}$ snlela7@gmail.com, ${ }^{2,}$ 'lilyani.lau@ @usamandiri.ac.id \\ Email Penulis Korespondensi: lilyani.lau@nusamandiri.ac.id
}

\begin{abstract}
Abstrak-Perkembangan industri otomotif di Indonesia dapat dikatakan sangat cepat dan cenderung meningkat tiap tahunnya, mengakibatkan tingginya kompetisi karena banyaknya perusahaan yang menyediakan berbagai macam merk sepeda motor dengan kualitas dan harga yang bersaing. Pihak perusahaan harus menciptakan strategi pemasaran yang mampu menambah tingkat efisiensi penjualan produk sepeda motor Yamaha. Untuk mengatasi masalah tersebut, dibutuhkan suatu strategi yang dapat membantu meningkatkan penjualan produk sepeda motor, yaitu dengan memanfaatkan data penjualan yang dimiliki oleh perusahaan. Data mining dapat digunakan untuk mengolah data penjualan perusahaan dengan mencari association rule dengan metode algoritma apriori pada variabel produk sepeda motor. Dari hasil analisis association rule pada data penjualan, dengan minimum support $30 \%$ dan minimum confidence $75 \%$ menghasilkan 3 rules dengan 3 produk yang paling banyak diminati konsumen yaitu NEW MIOM3 CW, NEWAEROX155VVA dan N-MAX, dengan diketahuinya produk yang paling banyak terjual, sehingga perusahaan dapat menambah persediaan produk yang paling banyak terjual dan menyusun strategi pemasaran untuk memasarkan produk dengan produk lain dengan meneliti apa kelebihan produk yang paling banyak terjual tersebut dengan produk lainnya.
\end{abstract}

Kata Kunci: Data Mining; Association Rule; Apriori; Sepeda Motor; Yamaha

Abstract-The development of automotive industry in Indonesia can be classifiedas very rapid and annually increasing, causing highly competitive circumstances because many companies provide various types of motorcycle brands with quality and competitive prices. The company must create a marketing strategy pattern that can increase the level of sales efficiency of Yamaha motorcycle products. To overcome this problem, a strategy that can help increasing sales of motorcycle products is needed, in which by utilizing sales data owned by the company. Data mining can be used to process company sales data by looking for association rules with apriori algorithm on motorcycle product variables. From the results of the association rule analysis on sales data, with a minimum support of $30 \%$ and a minimum confidence of $75 \%$ can produce 3 rules with 3 products that are most in demand by consumers, namely the NEW MIOM3 CW, NEWAEROX155VVA and N-MAX, by knowing the most selling products, the company can add the most selling product supply and develop a marketing strategy to market the products with other products by examining the comparative advantage of the most sold products over the other products.

Keywords: Data Mining; Association Rule; Apriori; Motorcycle; Yamaha

\section{PENDAHULUAN}

Kendaraan sepeda motor merupakan salah satu transportasi yang banyak diminati masyarakat Indonesia. Terlihat semakin banyaknya kendaraan sepeda motor yang memenuhi jalan-jalan di berbagai kota besar di Indonesia. Permintaan masyarakat terhadap sepeda motor terus mengalami peningkatan, hal ini memberikan peluang bagi para produsen sepeda motor untuk melakukan inovasi dari produk yang dihasilkannya [1]. Banyak hal yang menjadi alasan masyarakat lebih memilih sepeda motor sebagai sarana transportasi dibandingkan kendaraan lainnya. Sepeda motor menjadi kendaraan yang mudah digunakan bagi semua kalangan. Alasan terpenting orang memilih sepeda motor karena masyarakat ingin lebih cepat sampai tujuan dengan menghindari kemacetan lalu lintas. Peranan sepeda motor selain sebagai sarana mobilitas, juga memiliki manfaat lain yang dirasakan dalam menggunakan motor adalah lebih memiliki nilai ekonomis karena lebih hemat dibandingkan menggunakan mobil atau kendaraan umum.

Perkembangan industri otomotif di Indonesia dapat dikatakan sangat cepat dan cenderung meningkat tiap tahunnya, seiring perkembangan jaman dan juga daya beli masyarakat terhadap sepeda motor semakin meningkat karena saat ini proses pembelian sepeda motor makin mudah. Saat ini banyak merk dari produk sepeda motor yang ditawarkan seperti, Honda, Yamaha, Suzuki dan lain-lain.

Sepeda Motor merupakan kendaraan roda dua yang digerakkan oleh sebuah mesin. Letak kedua roda sebaris lurus dan pada kecepatan tinggi sepeda motor tetap stabil disebabkan oleh gaya giroskopik. Sedangkan pada kecepatan rendah, kestabilan atau keseimbangan sepeda motor tergantung kepada pengaturan stang oleh pengendara. Pengguna sepeda motor di Indonesia sangat populer karena harganya yang relatif murah, terjangkau untuk sebagian besar kalangan dan penggunaan bahan bakarnya serta biaya operasionalnya cukup hemat [2].

Yamaha merupakan sebuah perusahaan yang bergerak di bidang otomotif dengan persaingan yang sangat ketat karena banyak perusahaan-perusahaan yang bergerak di bidang yang sama dengan menghasilkan produk sejenis. Hal tersebut menyebabkan tingginya tingkat kompetisi karena banyaknya perusahaan yang menyediakan berbagai macam merk sepeda motor dengan kualitas dan harga yang bersaing. Pihak perusahaan harus menciptakan pola strategi pemasaran yang mampu menambah tingkat efisiensi penjualan produk sepeda motor Yamaha. 
Penjualan produk kendaraan sepeda motor pada salah satu perusahaan yang merupakan penyalur resmi dari produk sepeda motor Yamaha yaitu PT. Victory Cipta Makmur cabang Sukahati yang berlokasi di Jl. Raya Pemda Karadenan Bogor. Penjualan sepeda motor pada PT. Victory Cipta Makmur sudah meluas ke berbagai tempat, khususnya wilayah Jabodetabek. Disamping itu, data penjualan yang dihasilkannya pun telah bervolume cukup besar. Namun pada kenyataannya, perusahaan ini belum memanfaatkan secara optimal terhadap kumpulan dari banyaknya data transaksi penjualan yang tersimpan pada sistem penjualan perusahaan. Data tersebut dapat diamati untuk memastikan ketersediaan stok dan rekomendasi produk yang disukai oleh konsumen agar strategi pemasaran lebih terarah dan tepat sasaran. Jika data tersebut diolah dan dimanfaatkan menjadi informasi yang berguna dengan mencari pola penjualan produk sepeda motor, maka data ini bisa menjadi potensi yang menguntungkan bagi perusahaan dalam meningkatkan penjualan dan pemasaran produknya.

Terkadang hasil dari pengolahan data dengan cara sederhana (query) tidak mendapatkan hasil yang efektif karena besarnya volume data yang diolah dan kesulitan untuk melihat asosiasi antar jenis produk sepeda motor Yamaha. Perlu adanya suatu sistem yang dapat membantu secara cepat dan juga tepat. Pemanfaatan informasi dan pengetahuan yang terkandung di dalam banyaknya data disebut dengan data mining. Data mining membahas penggalian atau pengumpulan informasi yang berguna dari kumpulan data [3]. Volume data yang terus tumbuh berkembang secara dramatis, menyebabkan analisa data secara manual menjadi tidak praktis lagi. Dibutuhkan suatu solusi otomatis di bidang teknologi informasi untuk mengatasi permasalahan ini, yaitu data mining [4].

Terdapat beberapa permasalahan yang muncul mengenai penjualan produk perusahaan sulit mendapatkan informasi strategis seperti tingkat penjualan per periode, dengan menganalisa data perusahaan khususnya data penjualan dengan data mining menggunakan metode algoritma apriori maka akan dapat membantu dalam penggalian data yang sudah lama terjadi dan dapat dijadikan sebagai referensi di dalam manajemen perusahaan [5]. Menurut Dan Toomey dalam [6] Algoritma apriori adalah algoritma kelas yang membantu mempelajari peraturan asosiasi. Proses menggunakan algoritma apriori dimulai dengan menentukan kordinat pertama dan banyaknya pasangan data yang digunakan sebagai periode dasar. Kemudian mencari dua dan tiga kombinasi untuk mendapatkan nilai support dan confidence [7].

Market basket analysis dengan association rules merupakan salah satu cara untuk mencari pola asosiasi berdasarkan pola belanja yang dilakukan konsumen, seperti data transaksi minimarket. Banyak sekali pengaruh dalam pembelian konsumen, untuk itu perlu dianalisis sehingga dapat menghasilkan informasi yang bermanfaat untuk memaksimalkan keuntungan yang diperoleh. Hasil dari penelitian ini, support dan confidence tertinggi adalah biskuit dan makanan ringan [8]. Penyakit yang disebabkan oleh rokok lebih dari satu jenis penyakit, untuk mengetahui pola penyakit yang disebabkan oleh rokok dengan menganalisa data pasien rumah sakit. Algortima apriori bisa melakukan penelusuran pada data historis untuk mengidentifikasi pola data berdasarkan sifat yang teridentifikasi [9]. Dengan mencari pola kecenderungan pembelian obat, maka akan didapatkan informasi mengenai obat apa saja yang banyak dibeli dan yang sering dibeli secara bersamaan oleh konsumen. Dengan diketahui obat yang sering dibeli maka Apotek Zam-zam Farma Bogor dapat mengembangkan strategi pemasaran, mengatur stok obat agar tidak terjadi penumpukan obat maupun kekosongan obat dan mengatur tata letak penyimpanan obat yang sering dibeli secara bersamaan untuk mempermudah apoteker dalam mencari obat yang dibutuhkan guna mengoptimalkan pelayanan [10]. Untuk mengetahui mobil Honda yang paling diminati oleh konsumen dibutuhkan teknik Data Mining dengan metode Algoritma Apriori, dan didukung Aplikasi Tanagra dengan meneliti data penjualan selama 1 tahun. Maka hasil prediksi penelitian yang didapatkan, bahwa penjualan mobil Honda yang paling diminati konsumen adalah Mobil Brio Satya, HRV, Mobillio, Jazz, dan CRV [11]. Berdasarkan hasil penerapan Algoritma Apriori pada Perpustakaan FST UIN SUSKA Riau, dapat disimpulkan bahwa jika mahasiswa meminjam buku dengan kategori manajemen proyek atau kategori sistem pakar, maka mahasiswa tersebut juga akan meminjam buku kategori pemrograman. Aturan ini dapat digunakan pihak perpustakaan untuk mengatur tata letak buku dan rekomendasi peminjaman buku bagi mahasiswa [12]. Produk peralatan tulis yang sering dibeli oleh konsumen pada Toko XYZ menggunakan Algoritma Apriori adalah buku dan pulpen dengan tingkat support $60 \%$ dan tingkat confident $80 \%$. Banyaknya konsumen yang membeli produk tersebut, toko XYZ dapat memfokuskan produknya pada buku dan pulpen untuk penyediaan stok produk [13].

Berdasarkan uraian latar belakang di atas, maka dapat dikembangkan sebuah implementasi data mining dalam menentukan pola penjualan produk sepeda motor Yamaha pada PT. Victory Cipta Makmur. Diharapkan dengan mengetahui selera konsumen atau trend yang diminati konsumen sepeda motor Yamaha nantinya akan dijadikan sebagai alat bantu oleh pihak perusahaan PT. Victory Cipta Makmur dalam menentukan strategi pemasaran ke depan.

\section{METODOLOGI PENELITIAN}

\subsection{Tahapan Penelitian}

Tahapan penelitian yang dilakukan oleh peneliti dapat dilihat pada gambar 1 . 


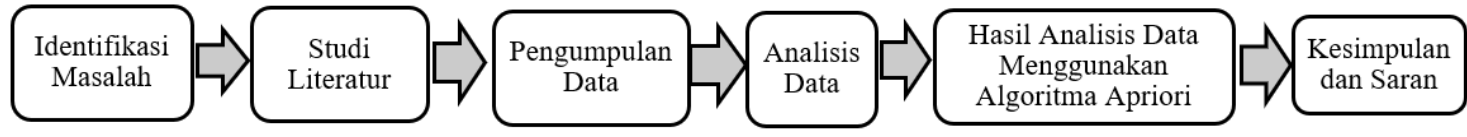

Gambar 1. Tahapan Penelitian

1. Identifikasi Masalah

Pada dasarnya semua penelitian akan selalu didahului dengan identifikasi masalah. Hal ini berguna untuk peneliti agar fokus pada titik permasalahan. Bagian ini perlu dituliskan berbagai masalah yang ada pada objek yang diteliti. Semua masalah dalam objek, baik yang akan diteliti maupun yang tidak akan diteliti sedapat mungkin dikemukakan.

2. Studi Literatur

Setelah masalah diidentifikasi, maka langkah kedua pada tahapan penelitian ini adalah mencari teori-teori, konsep-konsep dan generalisasi hasil penelitian yang dapat dijadikan sebagai landasan teoritis. Penulis melakukan studi pustaka dengan mencari sumber bacaan, bisa dalam bentuk buku-buku teks, jurnal ilmiah dan prosiding serta $e$-book tentang metode algoitma apriori yang digunakan sebagai acuan dalam menyelesaikan permasalahan yang terjadi pada PT. Victory Cipta Makmur.

3. Pengumpulan Data

Pengumpulan data pada penelitian ini melakukan pengamatan secara langsung (observasi) terhadap proses penjualan yang ada pada PT. Victory Cipta Makmur dan wawancara terhadap Sales Counter di PT. Victory Cipta Makmur, guna mendapatkan data primer dan data sekunder.

4. Analisis Data

Analisis Data merupakan kegiatan setelah data dari seluruh responden atau sumber data lain yang terkumpul. Setelah data terkumpul, maka selanjutnya dianalisis untuk menjawab rumusan masalah dan menguji hipotesis yang diajukan dengan teknik statistik tertentu. Penelitian ini menggunakan teknik statistik Data Mining menggunakan Association Rules dengan metode Algoritma Apriori. Data hasil analisis, selanjutnya disajikan dan diberikan pembahasan penyajian data dengan tabel dan grafik. Pembahasan terhadap hasil penelitian merupakan penjelasan yang mendalam dan interpretasi terhadap data-data yang telah disajikan.

5. Hasil Analisis Data Menggunakan Algoritma Apriori

Pada tahap ini penulis telah menyelesaikan analisis data dan mendapatkan hasil akhir dari penelitian, yaitu aturan asosiasi dengan Metode Algoritma Apriori.

6. Kesimpulan dan Saran

Setelah mendapatkan hasil dari penelitian, maka selanjutnya dapat disimpulkan. Kesimpulan berisi jawaban singkat terhadap setiap rumusan masalah berdasarkan data yang terlah terkumpul. Penulis melakukan penelitian bertujuan untuk memecahkan masalah, maka peneliti berkewajiban untuk memberikan saran-saran yang diharapkan dapat menyelesaikan masalah dan menjadi acuan dalam penelitian berikutnya.

\subsection{Instrumen Penelitian}

Instrumen penelitian adalah suatu alat yang digunakan mengukur fenomena alam maupun sosial yang diamati [14]. Kualitas instrumen penelitian berkenaan dengan validitas dan reliabilitas instrumen. Sedangkan kualitas pengumpulan data berkenaan ketepatan cara-cara yang digunakan untuk mengumpulkan data. Instrumen dalam penelitian kuantitatif dapat berupa test, pendoman wawancara, pendoman observasi dan kuesioner. Adapun alat yang digunakan dalam penelitian ini, sebagai berikut.

\section{A. Hardware}

Kebutuhan Perangkat Keras (Hardware) yang digunakan yaitu laptop Acer intel® Core ${ }^{\mathrm{TM}}$ i3 CPU M380 @ $2.53 \mathrm{GHz}$ (4 CPUs), harddisk dengan kapasitas 500 GB HDD.

B. Software

Kebutuhan Perangkat Lunak (Software) yang digunakan, yaitu:

1. Sistem Operasi Windows 7 Ultimate 32-bit

2. Microsoft Excel 2007sebagai media pengolah tabular dan akan dikoneksikan dengan Tanagra 1.4

3. Aplikasi Tanagra versi 1.4 yang digunakan untuk menampilkan presentasi knowledge yang dapat disimpulkan dari hasil penerapan model data mining.

\subsection{Metode Pengumpulan Data, Populasi, dan Sampel}

Beberapa teknik pengumpulan data dilihat dari segi cara yang dilakukan dalam penelitian ini adalah:

A. Metode Pengumpulan Data

1. Wawancara

Tujuan dari wawancara jenis ini adalah untuk menemukan permasalahan secara lebih terbuka, dimana pihak yang diajak wawancara diminta pendapat, dan ide - idenya. Peneliti mewawancarai salah satu pegawai atas nama Hariani Endakaninta selaku Sales Counter.

2. Observasi 
Metode ini dilakukan dengan melakukan pengamatan secara langsung terhadap proses penjualan yang ada di PT. Victory Cipta Makmur yang berhubungan dengan masalah yang diambil yang berlokasi Jl. Raya Pemda Karadenan no. 98, Cibinong, Bogor - 16913

\section{B. Populasi}

Populasi pada penelitian ini adalah data penjualan produk Sepeda Motor Yamaha bulan November 2020-April 2021 pada PT. Victory Cipta Makmur.

C. Sampel

Adapun sampel dalam penelitian ini adalah data penjualan produk Sepeda Motor Yamaha pada bulan November 2020-April 2021 di PT. Victory Cipta Makmur. Banyaknya sampel dari keseluruhan transaksi (bulan November 2020-April 2021) yang berjumlah 1.018 record.

\subsection{Metode Analisis Data}

Penelitian ini menggunakan analisis data dengan data mining menggunakan teknik association rules dengan metode algoritma apriori. Adapun tahapan analisis data dalam penelitian ini, yaitu:

A. Analisa Permasalahan di PT. Victory Cipta Makmur

Dalam proses ini, peneliti menganalisis permasalahan yang ada pada PT. Victory Cipta Makmur, khususnya pada proses penjualan yang ada. Analisis data penjualan dengan menggunakan metode algoritma apriori.

B. Pengolahan Data dengan Perhitungan Algoritma Apriori

Tahapan yang dilakukan dalam perhitungan dengan algoritma apriori yaitu:

1. Mencari 3 nilai terbesar yang paling banyak terjual.

Untuk langkah pertama yaitu dengan mencari nilai penjualan yang paling tinggi dalam suatu data transaksi tiap bulan dengan langkah-langkah:

a. Menentukan daftar merk sepeda motor Yamaha.

b. Menentukan data penjualan produk sepeda motor Yamaha.

2. Melakukan pengelompokkan 3 merk sepeda motor yang paling laku terjual.

3. Melakukan representasi data transaksi yang direpresentasikan ke dalam bentuk tabel.

4. Bila diketahui produk sepeda motor serta jumlah transaksi terbesar setiap bulannya, maka dibuat format tabular agar dapat dianalisis dengan algortima apriori.

5. Analisis pola frekuensi tinggi.

Analisis pola frekuensi tertinggi menghasilkan kombinasi item yang memenuhi syarat minimum support yang sudah ditentukan [15]. Support merupakan suatu ukuran yang menunjukkan seberapa besar tingkat dominasi suatu item atau itemset dari keseluruhan transaksi [16]. Tahap ini mencari kombinasi item yang memenuhi syarat minimum dari nilai nilai support dalam database. Nilai support sebuah item diperoleh dengan rumus berikut:

$$
\text { Support }(\mathrm{A})=\frac{\sum \text { transaksi mengandung A }}{\sum \text { transaksi }} \times 100 \%
$$

Sementara itu, rumus 2 itemset diperoleh dengan rumus:

$$
\begin{aligned}
& \text { Support }(\mathrm{A}, \mathrm{B})=\mathrm{P}(\mathrm{A} \cap \mathrm{B}) \\
& \text { Support }(\mathrm{A}, \mathrm{B})=\frac{\sum \text { transaksi mengandung } \mathrm{A} \text { dan B }}{\sum \text { transaksi }} \times 100 \%
\end{aligned}
$$

6. Pembentukan Aturan Asosiasi.

Pembentukan pola association rule dilakukan untuk menemukan aturan asosiasi yang memenuhi minimum confidence dari frekuensi tinggi yang telah ditemukan [15]. Confidence merupakan suatu ukuran yang menunjukkan hubungan antar dua item secara conditional (berdasarkan suatu kondisi tertentu) [16]. Setelah semua pola frekuensi tinggi ditemukan, pencarian aturan asosiasi akan dilakukan dengan syarat minimum untuk confidence dengan menghitung confidence atau asosiatif $\mathrm{A} \rightarrow \mathrm{B}$. Nilai confidence diperoleh dari rumus berikut:

$$
\text { Confidence }=\mathrm{P}(\mathrm{B} \mid \mathrm{A})=\frac{\sum \text { transaksi mengandung } \mathrm{A} \text { dan } \mathrm{B}}{\sum \text { transaksi mengandung } \mathrm{A}} \times 100 \%
$$

Pencarian nilai confidence juga dilakukan sampai nilai tidak memenuhi syarat minimum confidence lagi.

7. Aturan Asosiasi Final

Dari analisis yang telah dilakukan dalam tahapan ini akan terlihat asosiasi yang terbentuk dengan menggunakan perhitungan algoritma apriori.

C. Implementasi Algoritma Apriori dengan Tanagra 1.4

Tanagra 1.4 merupakan salah satu software data mining yang di dalamnya terdapat beberapa metode data mining. Tanagra dapat digunakan oleh semua orang karena bersifat open source [17]. Pada tahapan sebelumnya, analisis data dengan algoritma apriori dilakukan secara manual atau menggunakan rumus yang telah ditentukan dan menganalisis/ menghitung hasil dari analisis data itu sendiri, maka selanjutnya akan 
dilakukan analisis secara otomatis dengan menggunakan aplikasi Tanagra 1.4 untuk membandingkan dan mengecek apakah proses perhitungan manual dan otomatis sama.

\section{HASIL DAN PEMBAHASAN}

PT. Victory Cipta Makmur menawarkan produk sepeda motor dengan brand Yamaha. Inovasi selalu dilakukan oleh Yamaha untuk mengembangkan produk sepeda motornya, sehingga banyak sekali jenis atau merk yang ditawarkan. Berikut 30 merk yang ditawarkan dapat terlihat pada Tabel 1.

Tabel 1. Daftar Jenis Sepeda Motor Yamaha

\begin{tabular}{clcl}
\hline No. & \multicolumn{1}{c}{ Jenis Motor Yamaha } & No. & \multicolumn{1}{c}{ Jenis Motor Yamaha } \\
\hline 1 & ALL NEW VIXION & 16 & NEW FINO PR BC \\
2 & ALLNEWVIXION R & 17 & NEW FINO SP BC \\
3 & ALLNEWVIXIONGP & 18 & NEW MIO M3 CW \\
4 & ALLNEWXRIDE125 & 19 & NEW MIO M3 CW S \\
5 & FINOGRANDE125 & 20 & NEWAEROX155VVA \\
6 & JUPZCW FI & 21 & NEWAEROXVVARV \\
7 & LEXI & 22 & NEWAEROXVVASV \\
8 & LEXI S & 23 & NEWSOULGTA \\
9 & MIOM3AKSSSS & 24 & NEWSOULGTAKS \\
10 & MIOM3CW & 25 & N-MAX \\
11 & MIOS & 26 & NMAX ABS \\
12 & MT25 & 27 & R15 GP MOVISTAR \\
13 & MX KING & 28 & R15VVA155 \\
14 & MX KING GP MOV & 29 & XABRE \\
15 & NEW AEROX - S V & 30 & XMAX \\
\hline
\end{tabular}

Transaksi penjualan produk sepeda motor Yamaha akan diakumulasikan dan disusun berdasarkan jumlah penjualan tiga produk terbesar setiap bulannya. Setelah data transaksi penjualan dikelompokkan per bulannya, maka tahap selanjutnya akan terbentuk pola transaksi penjualan, seperti pada Tabel 2.

Tabel 2. Pola Transaksi Penjualan Sepeda Motor Yamaha

\begin{tabular}{cl}
\hline Bulan & \multicolumn{1}{c}{ Itemset } \\
\hline November 2020 & N-MAX, NEWAEROX155VVA, NEW MIO M3 CW \\
Desember 2020 & N-MAX, NEWAEROX155VVA, MX KING \\
Januari 2021 & N-MAX, MX KING. MIOM3 CW \\
Februari 2021 & N-MAX, NEWAEROX155VVA, NEW FINO PR BC \\
Maret 2021 & N-MAX NEWAEROX155VVA, MIOM3 CW \\
April 2021 & N-MAX, NEWAEROX155VVA, NEW MIO M3 CW \\
\hline
\end{tabular}

Hasil bentuk Pola Transaksi penjualan dilanjutkan dengan proses representasi data transaksi, dapat dilihat dalam tabel 3.

Tabel 3. Representasi Data Transaksi

\begin{tabular}{cc}
\hline Transaksi & Item Terjual \\
\hline November 2020 & N-MAX \\
November 2020 & NEWAEROX155VVA \\
November 2020 & NEW MIOM3 CW \\
Desember 2020 & N-MAX \\
Desember 2020 & NEWAEROX155VVA \\
Desember 2020 & MX-KING \\
Januari 2021 & N-MAX \\
Januari 2021 & MX KING \\
Januari 2021 & MIOM3 CW \\
Februari 2021 & N-MAX \\
Februari 2021 & NEWAEROX155VVA \\
Februari 2021 & NEW FINO PR BC \\
Maret 2021 & N-MAX \\
Maret 2021 & NEWAEROX155VVA
\end{tabular}


ISSN 2614-5278 (media cetak), ISSN 2548-8368 (media online)

Available Online at https://ejurnal.stmik-budidarma.ac.id/index.php/mib DOI 10.30865/mib.v5i3.3112

\begin{tabular}{cc}
\hline Transaksi & Item Terjual \\
\hline Maret 2021 & MIOM3 CW \\
April 2021 & NEW MIO M3 CW \\
April 2021 & NEWAEROX155VVA \\
April 2021 & N-MAX \\
\hline
\end{tabular}

Format tabular data transaksi bulanan bila dibentuk akan terlihat seperti pada Tabel 4 .

Tabel 4. Format Tabular Transaksi Perbulan

\begin{tabular}{ccccccc}
\hline Bulan & MIOM3_CW & $\begin{array}{c}\text { MX_KI } \\
\text { NG }\end{array}$ & $\begin{array}{c}\text { NEWAEROX } \\
\text { 155VVA }\end{array}$ & $\begin{array}{c}\text { NEW_FINO } \\
\text { _PR_BC }\end{array}$ & $\begin{array}{c}\text { NEW_MI } \\
\text { OM3_CW }\end{array}$ & N-MAX \\
\hline November 2020 & 0 & 0 & 1 & 0 & 1 & 1 \\
Desember 2020 & 0 & 1 & 1 & 0 & 0 & 1 \\
Januari 2021 & 1 & 1 & 0 & 0 & 0 & 1 \\
Februari 2021 & 0 & 0 & 1 & 1 & 0 & 1 \\
Maret 2021 & 1 & 0 & 1 & 0 & 0 & 1 \\
April 2021 & 0 & 0 & 1 & 0 & 1 & 1 \\
$\Sigma$ & 2 & 2 & 5 & 1 & 2 & 6 \\
\hline
\end{tabular}

Persentase jumlah item terpilih dan yang memenuhi syarat minimum support sebesar $30 \%$ dari data transaksi dapat dilihat pada tabel 5, tabel 6, dan tabel 7 .

Tabel 5. Kombinasi 1 Itemset yang Memenuhi Syarat

\begin{tabular}{ccc}
\hline Itemset & Jumlah & Hasil Support \\
\hline MIOM3 CW & 2 & $33,33 \%$ \\
MX KING & 2 & $33,33 \%$ \\
NEWAEROX155VVA & 5 & $83,33 \%$ \\
NEW MIOM3 CW & 2 & $33,33 \%$ \\
N-MAX & 6 & $100 \%$ \\
\hline
\end{tabular}

Tabel 6. Kombinasi 2 Itemset yang Memenuhi Syarat

\begin{tabular}{ccc}
\hline Itemset & Jumlah & Hasil Support \\
\hline MIOM3 CW - N-MAX & 2 & $33,33 \%$ \\
MX KING - N-MAX & 2 & $33,33 \%$ \\
NEWAEROX155VVA - NEW MIOM3 CW & 2 & $33,33 \%$ \\
NEWAEROX155VVA - N-MAX & 5 & $83,33 \%$ \\
NEW MIOM3 CW - N-MAX & 2 & $33,33 \%$ \\
\hline
\end{tabular}

Tabel 7. Kombinasi 3 Itemset yang Memenuhi Syarat

\begin{tabular}{ccc}
\hline Itemset & Jumlah & Hasil Support \\
\hline NEWAEROX155VVA - NEW MIOM3 CW - N-MAX & 2 & $33,33 \%$ \\
\hline
\end{tabular}

Pada tabel 7 telah disimpulkan bahwa item yang sering dibeli bersamaan adalah NEWAEROX155VVA, NEW MIOM3 CW dan N-MAX, untuk mengetahui nilai confidence, itemset (NEWAEROX155VVA, NEW MIOM3 CW, N-MAX) dibuatkan aturan asosiatifnya, hasilnya seperti pada Tabel 8.

Tabel 8. Pembentukan Aturan Asosiatif

\begin{tabular}{lccc}
\hline \multicolumn{1}{c}{ Aturan Asosiatif } & $\begin{array}{c}\text { Support } \\
\text { (AUB) }\end{array}$ & $\begin{array}{c}\text { Support } \\
(\mathrm{A})\end{array}$ & $\begin{array}{c}\text { Confidence } \\
\%\end{array}$ \\
\hline NEWAEROX155VVA $\rightarrow$ NEW MIOM3 CW, N-MAX & 2 & 5 & $40 \%$ \\
NEW MIOM3 CW $\rightarrow$ NEWAEROX155VVA, N-MAX & 2 & 2 & $100 \%$ \\
N-MAX $\rightarrow$ NEW MIOM3 CW, NEWAEROX155VVA & 2 & 6 & $33,33 \%$ \\
NEW MIOM3 CW, N-MAX $\rightarrow$ NEWAEROX155VVA & 2 & 2 & $100 \%$ \\
NEWAEROX155VVA, N-MAX $\rightarrow$ NEW MIOM3 CW & 2 & 5 & $40 \%$ \\
NEW MIOM3 CW NEWAEROX155VVA $\rightarrow$ N-MAX & 2 & 2 & $100 \%$ \\
NEW MIOM3 CW $\rightarrow$ N-MAX & 2 & 2 & $100 \%$ \\
NEWAEROX155VVA $\rightarrow$ N-MAX & 5 & 5 & $100 \%$ \\
NEW MIOM3 CW $\rightarrow$ NEWAEROX155VVA & 2 & 2 & $100 \%$ \\
\hline
\end{tabular}


ISSN 2614-5278 (media cetak), ISSN 2548-8368 (media online)

Available Online at https://ejurnal.stmik-budidarma.ac.id/index.php/mib

DOI 10.30865/mib.v5i3.3112

Tabel 9. Aturan Asosiasi Final

\begin{tabular}{lcc}
\hline \multicolumn{1}{c}{ Itemset } & Support & Confidence \\
\hline NEW MIOM3 CW $\rightarrow$ NEWAEROX155VVA, N-MAX & $33,33 \%$ & $100 \%$ \\
NEW MIOM3 CW, N-MAX $\rightarrow$ NEWAEROX155VVA & $33,33 \%$ & $100 \%$ \\
NEW MIOM3 CW, NEWAEROX155VVA $\rightarrow$ N-MAX & $33,33 \%$ & $100 \%$ \\
NEW MIOM3 CW $\rightarrow$ N-MAX & $33,33 \%$ & $100 \%$ \\
NEWAEROX155VVA $\rightarrow$ N-MAX & $33,33 \%$ & $100 \%$ \\
NEW MIOM3 CW $\rightarrow$ NEWAEROX155VVA & $33,33 \%$ & $100 \%$ \\
\hline
\end{tabular}

Berdasarkan tabel 9, dapat disimpulkan bahwa produk yang diminati oleh konsumen adalah NEW MIOM3 CW, NEWAEROX155VVA dan N-MAX dan dapat dilihat pada gambar 2.

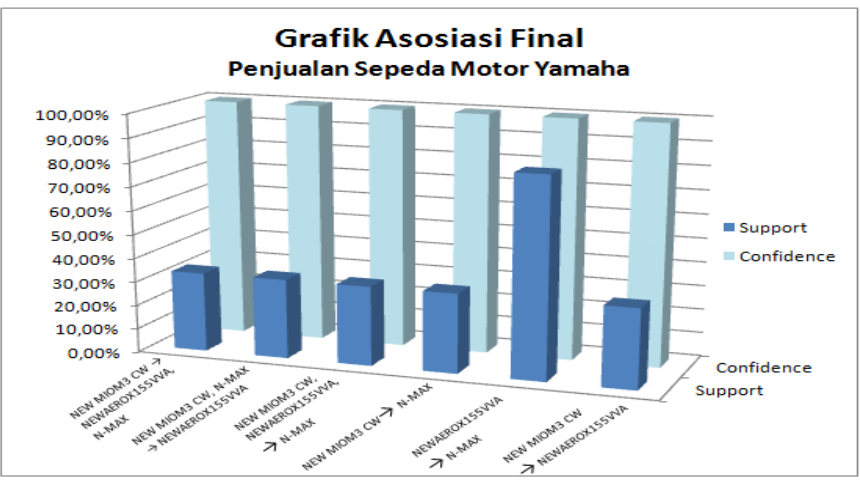

Gambar 2. Grafik Aturan Asosiasi Final Penjualan Terbanyak

Hasil asosiasi final atribut yang memenuhi syarat minimum support dan minimum confidence adalah NEW MIOM3 CW, N-MAX dan NEWAEROX155VVA terlihat pada gambar 3.

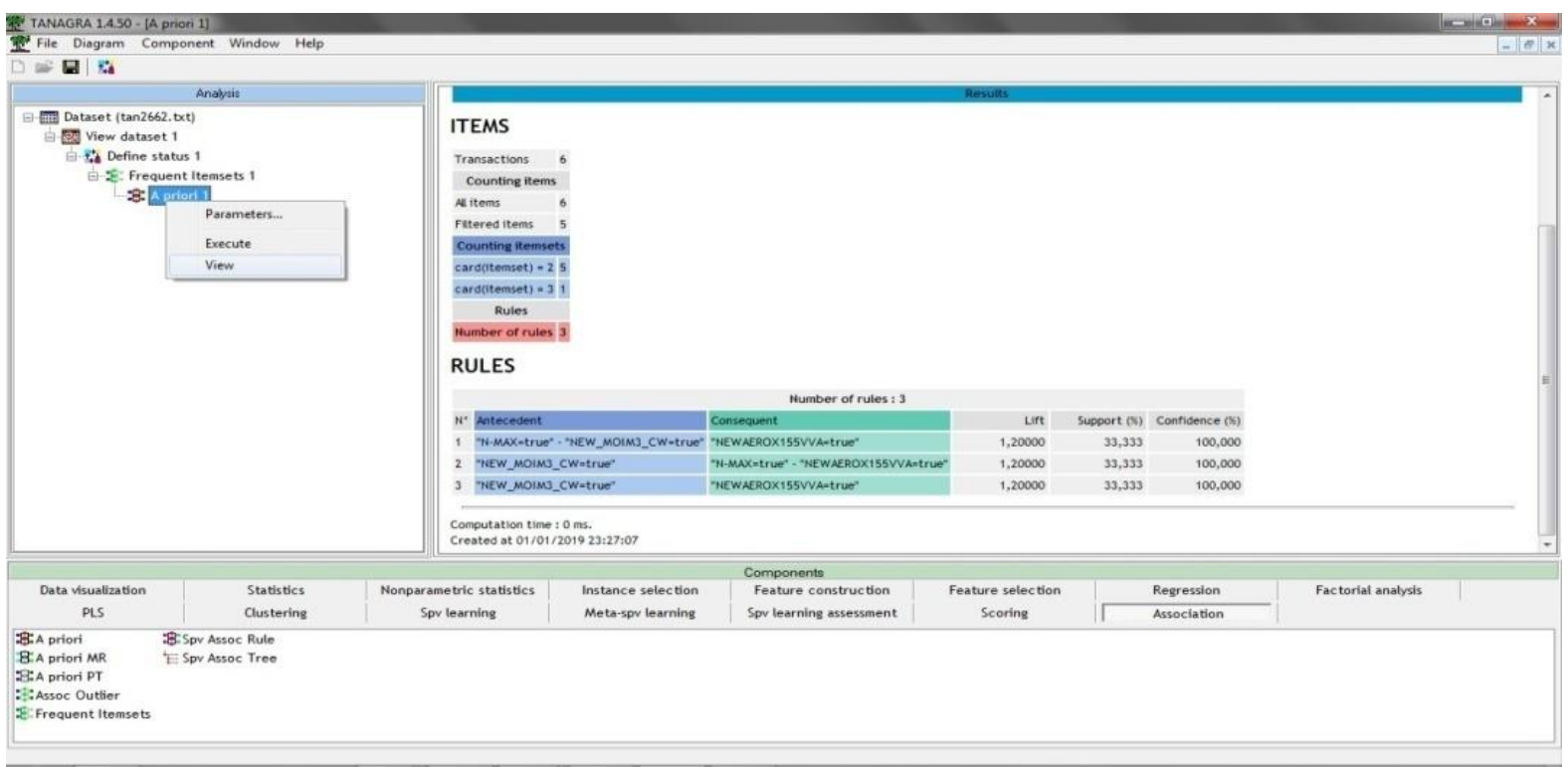

Gambar 3. Hasil Asosiasi Final

Aturan asosiasi final atau Association Rules berdasarkan pada minimum support dan minimum confidence yang telah diatur, maka dihasilkan aturan asosiasi pada tabel 10.

Tabel 10. Hasil Aturan Asosiasi Final

\begin{tabular}{|c|c|c|}
\hline Aturan & Support & Confidence \\
\hline $\begin{array}{c}\text { Jika membeli N-MAX dan NEW MIOM3 CW, maka akan membeli } \\
\text { NEWAEROX155VVA }\end{array}$ & $33,33 \%$ & $100 \%$ \\
\hline $\begin{array}{l}\text { Jika membeli NEW MIOM3 CW, maka akan membeli N-MAX dan } \\
\text { NEWAEROX155VVA }\end{array}$ & $33,33 \%$ & $100 \%$ \\
\hline $\begin{array}{l}\text { Jika membeli NEW MIOM3CW maka akan membeli } \\
\text { NEWAEROX155VVA }\end{array}$ & $33,33 \%$ & $100 \%$ \\
\hline
\end{tabular}


ISSN 2614-5278 (media cetak), ISSN 2548-8368 (media online)

Available Online at https://ejurnal.stmik-budidarma.ac.id/index.php/mib DOI 10.30865/mib.v5i3.3112

Berdasarkan aturan asosiasi diatas, dapat diketahui bahwa produk sepeda motor Yamaha yang paling banyak terjual pada PT. Victory Cipta Makmur dapat dilihat pada gambar 4.

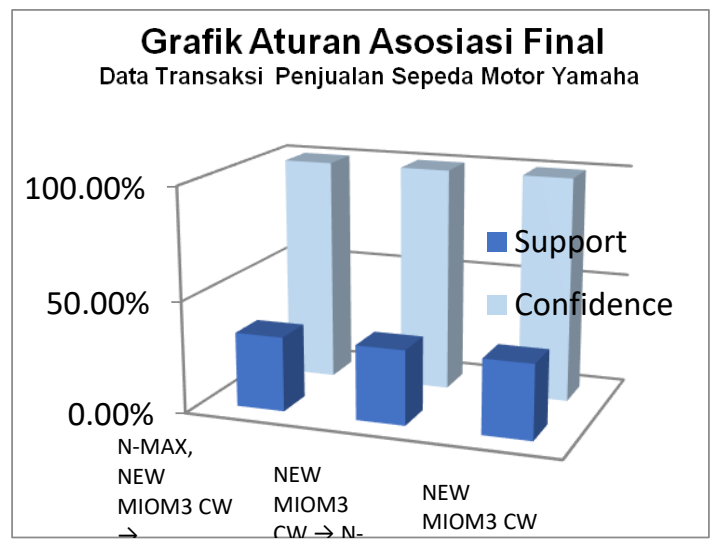

Gambar 4. Grafik Aturan Asosiasi Final Penjualan Terbanyak

Berdasarkan grafik di atas, produk sepeda motor Yamaha yang paling banyak terjual adalah NEW MIOM3 CW, NEWAEROX155VVA dan N-MAX, dengan diketahuinya produk yang paling banyak terjual, sehingga perusahaan dapat menambah persedian produk yang paling banyak terjual dan menyusun strategi pemasaran untuk memasarkan produk dengan produk lain dengan meneliti apa kelebihan produk yang paling banyak terjual tersebut dengan produk lainnya.

\section{KESIMPULAN}

Menganalisa algoritma apriori terhadap data penjualan produk sepeda motor Yamaha pada PT. Victory Cipta Makmur, dimulai dari menganalisa data tersebut dengan cara mencari pola frekuensi tinggi lalu menentukan syarat minimum support dan minimum confidence dengan frequent itemset dan algoritma apriori untuk mendapatkan hasil aturan asosiasi yang memenuhi support dan confidence. Data Mining dapat diimplementasikan dengan menggunakan database penjualan produk sepeda motor Yamaha pada PT. Victory Cipta Makmur untuk menemukan kecenderungan pola kombinasi itemset, dengan diketahui aturan asosiasi dapat membantu PT. Victory Cipta Makmur dalam menentukan produk sepeda motor apa saja yang menjadi selera konsumen sehingga pihak manajemen dapat menyusun strategi penjualan. Penerapan algoritma apriori dapat diimplementasikan pada aplikasi Tanagra. Hal ini dibuktikan melalui perhitungan nilai support dan confidence yang menunjukan hasil yang sama.

\section{REFERENCES}

[1] N. Fatmawati and E. Soliha, "Kualitas Produk, Citra Merek dan Persepsi Harga Terhadap Proses Keputusan Pembelian Konsumen Sepeda Motor Matic 'Honda," J. Manaj. Teor. dan Terap.|J. Theory Appl. Manag., vol. 10, no. 1, p. 1, 2017, doi: 10.20473/jmtt.v10i1.5134.

[2] H. Soedarmo, Panduan Praktis Merawat \& Memperbaiki Sepeda Motor. PT. Gramedia Pustaka Utama., 2018.

[3] S. Adinugroho and Y. A. Sari, Implementasi Data Mining Menggunakan Weka. Malang: Universitas Brawijaya Press, 2018.

[4] Purwadi, "Implementasi Data Mining Untuk Memprediksi Pola Pembelian Sepeda Motor Pada Showroom Cv . Viva Mas Motors Dengan Metode Algoritma C4 . 5," J. Sist. Inf. Kaputama, vol. 2, no. 2, pp. 34-38, 2018.

[5] P. Sari and B. Sinaga, "APLIKASI DATA MINING DENGAN MENGGUNAKAN ALGORITMA APRIORI UNTUK PENJUALAN PRODUK TERBESAR PADA CV. SAKURA PHOTO,” Eur. Heart J., vol. 28, no. 12, pp. 1407-1408, 2018.

[6] S. Sulastri, E. Zuliarso, and Y. Anis, "Implementasi Algoritma Apriori Dan Algoritma Eclat Pada Ahass Akmal Jaya Purwodadi," Dinamik, vol. 22, no. 1, pp. 50-56, 2017, doi: 10.35315/dinamik.v22i1.7105.

[7] P. Studi et al., "ANALISIS ALGORITMA APRIORI DAN ASSOCIATION RULE DALAM MENENTUKAN PERSEDIAAN SPARE PART MOTOR PADA PT .," pp. 122-128, 2020.

[8] E. L. Febrianti and A. Suryadi, "Penerapan Data Mining Dengan Algoritma Apriori," vol. 9986, no. September, pp. 1-4, 2018.

[9] F. T. Waruwu, E. Buulolo, and E. Ndruru, "Implementasi Algoritma Apriori Pada Analisa Pola Data Penyakit Manusia Yang Disebabkan Oleh Rokok," KOMIK (Konferensi Nas. Teknol. Inf. dan Komputer), vol. I, no. 1, pp. 176-182, 2017.

[10] A. Ishaq, L. A. Utami, and S. Mariana, "Analisa Pola Penjualan Obat Menggunakan Algoritma Apriori Pada Apotek Zam-Zam Bogor," Syntax J. Inform., vol. 08 No. 1, no. 1, pp. 13-23, 2019, [Online]. Available: https://repository.nusamandiri.ac.id/index.php/unduh/item/221312/utami.pdf.

[11] D. Anggraini, S. A. Putri, and L. A. Utami, "Implementasi Algoritma Apriori Dalam Menentukan Penjualan Mobil Yang Paling Diminati Pada Honda Permata Serpong," J. Media Inform. Budidarma, vol. 4, no. 2, p. 302, 2020, doi: 10.30865/mib.v4i2.1496. 
ISSN 2614-5278 (media cetak), ISSN 2548-8368 (media online)

Available Online at https://ejurnal.stmik-budidarma.ac.id/index.php/mib DOI 10.30865/mib.v5i3.3112

[12] E. Srikanti, R. F. Yansi, Norhavina, I. Permana, and F. N. Salisah, "Penerapan Algoritma Apriori untuk Mencari Aturan Asosiasi pada Data Peminjaman Buku di Perpustakaan,” J. Ilm. Rekayasa dan Manaj. Sist. Inf., vol. 4, no. 1, pp. 77-80, 2018.

[13] A. Valerian and L. Hakim, "Implementasi Algoritma Apriori Untuk Prediksi Stok Peralatan Tulis Pada Toko XYZ,” J. Ilm. Teknol. Inf. Terap., vol. V, no. 1, pp. 18-22, 2018.

[14] Sugiyono, Metode Penelitian Kuantitatif, Kualitatif, dan R\&D, 27th ed. Bandung: Alfabeta, 2017.

[15] A. R. Riszky and M. Sadikin, "Data Mining Menggunakan Algoritma Apriori untuk Rekomendasi Produk bagi Pelanggan,” J. Teknol. dan Sist. Komput., vol. 7, no. 3, pp. 103-108, 2019, doi: 10.14710/jtsiskom.7.3.2019.103-108.

[16] S. Sutrisno, "Penerapan Algoritma Apriori Untuk Mencari Pola Penjualan Produk Dana Pada Pt Bank Rakyat Indonesia (Persero) Tbk Kanca Jakarta Pasar Minggu," J. Sist. Inf. dan Inform., vol. 3, no. 1, pp. 12-26, 2020, doi: 10.47080/simika.v3i1.834.

[17] S. Adrianto, N. Khasanah, and D. Wahyuni, "Implementasi Data Mining pada Penjualan Kartu Perdana Internet di Purnama Ponsel Menggunakan Metode Algoritma Apriori," JISKA (Jurnal Inform. Sunan Kalijaga), vol. 5, no. 2, pp. 81-95, 2020, doi: 10.14421/jiska.2020.52-03. 